\title{
INDUCTIVE HIGH POWER TRANSFER TECHNOLOGIES FOR ELECTRIC VEHICLES
}

\author{
Nikolay D. Madzharov - Anton T. Tonchev *
}

\begin{abstract}
Problems associated with "how to charge the battery pack of the electric vehicle" become more important every passing day. Most logical solution currently is the non-contact method of charge, possessing a number of advantages over standard contact methods for charging. This article focuses on methods for Inductive high power contact-less transfer of energy at relatively small distances, their advantages and disadvantages. Described is a developed Inductive Power Transfer (IPT) system for fast charging of electric vehicles with nominal power of $30 \mathrm{~kW}$ over 7 to $9 \mathrm{~cm}$ air gap.
\end{abstract}

K e y w ords: inductive power transfer, IPT, electric vehicles (EV), charging station, transformer, magnetic field

\section{INTRODUCTION}

One of the fastest - growing industries (just emerging) is the electrical automotive industry. This course is the opportunity, expected by many scientists to promote contactless inductive method of transferring energy.

Already in use are the first charging stations for electric vehicles based on connectors and cables. Along with them, however, first prototypes of contactless charging systems are fact, providing the ability to transfer 3 to $15 \mathrm{~kW}$ up to 80 to $250 \mathrm{~mm}$ distance [5]. They represent a whole class of devices appropriate to charge the battery pack during the stay of the electric vehicle in the garage (home), the parking lot, during the stay at traffic lights, every place in urban and extra-urban conditions. Unfortunately, most - simple calculations made suggest at least 8 to 10 hours of full charge, which makes them almost not applicable for fast and "on-route" charging (up to speeds of $30 \mathrm{~km} / \mathrm{h}$ ) of EV [1]. "Achilles heel" of any electric propulsion is not the electricity, but the energy source. Cycles of charge and discharge of the battery is an integral part of the problem with turning an idea for mass usage of electrical vehicle into reality, Fig1. In standard cars time to refuel (full tank) is not more than 20 to $30 \mathrm{~min}$ for the whole procedure, and time to burn the fuel at an average speed of $100 \mathrm{~km} / \mathrm{h}$ is over 8 to 10 hours [1]. One possibility here is the on-route charging. Its implementation is possible at this stage just using IPT principle. In order to improve the accumulation of electricity during the frequent and shorter cycles of charging on the road high capacity energy buffers can be used ("super-capacitors").They are also useful for increasing the dynamics of the EV in accelerations and rapid energy accumulation during braking processes [2].

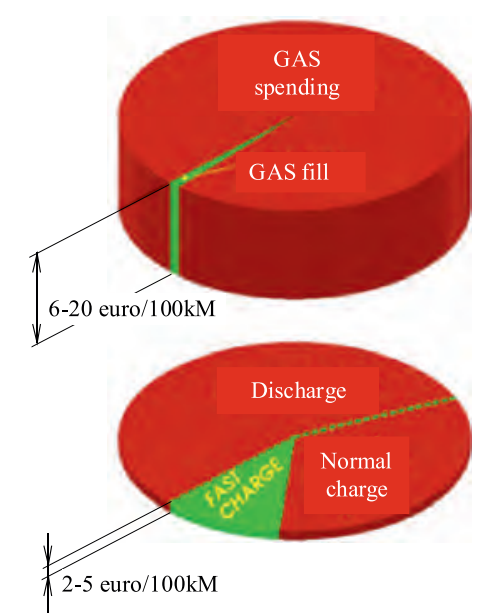

Fig. 1. Combustion engine car refuel/spend and electric car charge/discharge cycles

\section{BASIC IPT TECHNOLOGIES}

In essence the combination of Receiver and Transmitter can be considered as a loosely coupled equivalent transformer. The amount of used air gap between the coils leads to several key differences:

- At air gap more that $60 \mathrm{~mm}$ there is no need of mechanical connection and precise positioning for the equivalent transformer;

- For air gap less than $60 \mathrm{~mm}$ is typical high power density and small volume, but also difficult mechanical coupling process between primary and secondary side main disadvantage of this method. The IPT efficiency in this case is better, Table 1 .

The strong influence of the air gap values, causing rapid changes of magnetic permeability of the equiva-

\footnotetext{
* Department of electronics, Technical University of Gabrovo, 5300 Bulgaria, madjarov@tugab.bg
} 
Table 1. Comparison of different air gap configurations

Equivalent transformer air gaps

\begin{tabular}{lcc} 
Parameter & Air gap 120 to $60 \mathrm{~mm}$ & Air gap 13 to $8 \mathrm{~mm}$ \\
\hline Transferred power & $25-35 \mathrm{~kW}$ & $25-45 \mathrm{~kW}$ \\
Frequency span & $10-80 \mathrm{kHz}$ & $50-500 \mathrm{kHz}$ \\
Diameter app. & $800 \mathrm{~mm}$ & $300 \mathrm{~mm}$ \\
Weight & $46-64 \mathrm{~kg}$ (both coils) & $16-26 \mathrm{~kg}$ (both coils) \\
Power density & $500-600 \mathrm{~W} / \mathrm{kg}$ & $1400-1800 \mathrm{~W} / \mathrm{kg}$ \\
\hline \multirow{3}{*}{ Advantages } & (i) Fully contact-less method & (i) Electrically (only) \\
& (ii) Can be used even on the road & contact-less method \\
& (iii) Larger missaligment not-critical & (ii) High power density \\
\hline \multirow{2}{*}{ Disadvantages } & (i) Smaller power density & (i) Need of precision positioning system \\
& (ii) Need of electromagnetic shield & (ii) Not enough robust \\
\hline
\end{tabular}

lent transformer can be significantly improved using overlapping in the area of the air gap between cores of the transformer (Fig.2.). This technique provides decreasing of magnetic path length and magnetization current of the transformer.

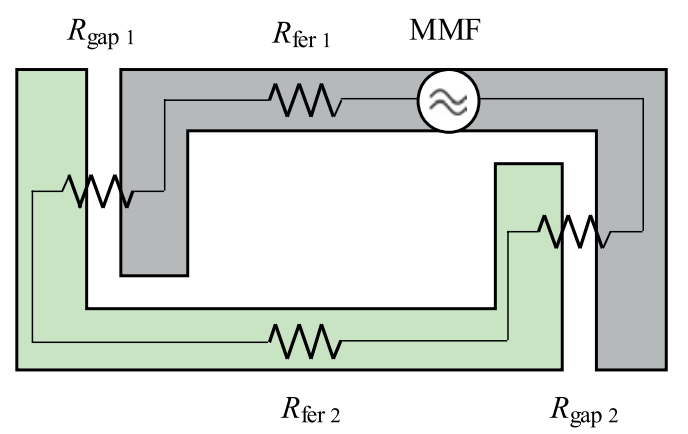

Fig. 2. Equivalent magnetic circuit with "overlapping"

The expression for the magnetic reluctance of the air gap is corrected by a factor $K_{A} \neq 1$, which is used for adjustments due to the increased equivalent cross section in the air gap zone

$$
R_{\text {gap }}=\frac{l_{\text {gap }}}{\mu_{0} A_{f e r} K_{A}}
$$

where $K_{A}<A_{\text {gap }} / A_{\text {fer }}$. It can be noted that $K_{A}$ is a coefficient, which is analogous to the magnetic permeability of the ferrite core and its influence grows as the ratio of $\mu_{r} / K_{A}$ decreases, ie for cases with low magnetic permeability of the material and/or large equivalent air gap cross section [1].

\section{$330 \mathrm{~kW} \& 70 \mathrm{~mm}$ IPT EV CHARGING CONVERTER}

The developed IPT System is based on long term study of Inductive Power Transfer Techniques and existing problems in that area (Table2.) $[9,10]$. One of the key points laid down in the beginning of the design is faster charging for short time, so-called High power transfer.

Table 2. Parameters of $30 \mathrm{~kW} \& 70 \mathrm{~mm}$ IPT System

\begin{tabular}{lr} 
Parameter & Value \\
\hline Nominal input power & $30 \mathrm{kVA}$ \\
Efficiency & up to $92 \%$ \\
Nominal output voltage & $400 \mathrm{~V} \mathrm{DC}$ \\
Nominal output current & $75 \mathrm{~A} \mathrm{DC}$ \\
Converter frequency & $20 \mathrm{kHz}-12 \mathrm{kHz}$ \\
Coil mass & $700 \mathrm{~mm} \times 800 \mathrm{~mm}$ \\
Gap & $\times 90 \mathrm{~mm}: 28 \mathrm{~kg}$ \\
Horizontal misalignment & $\Delta X=\Delta Z= \pm 150 \mathrm{~mm}$ \\
\hline
\end{tabular}

In Figure 4 a simplified topology of the power electronics of the converter is presented. As the prototype is designed for testing and demonstration of static and dynamic mode (at the time of motion) an advanced model of a standard full bridge converter is used. The total number of used transistor modules is 5 - one common IGBT module and 4 separate for each coil (Fig.4). During the movement of EV across the coils only one of four modules are enabled (IGBT1,2,3 or 4) to form a full bridge converter with the common module IGBT - COM. The period of operation of each coil (switching on and off moments) can be determined by feedback from a sensor or algorithm working in the inverter itself (sensorless). This technique reduces the price of the prototype (one hybrid Full bridge, instead of 4 different full bridge inverters) but also makes impossible the simultaneous work of the transmitting (charging) coils.

The air gap between the primary and secondary coils is $\Delta Y=70--90 \mathrm{~mm}$ and the horizontal misalignment of $\Delta X=\Delta Z= \pm 150 \mathrm{~mm}$. Maximum output peak power 
E-Car

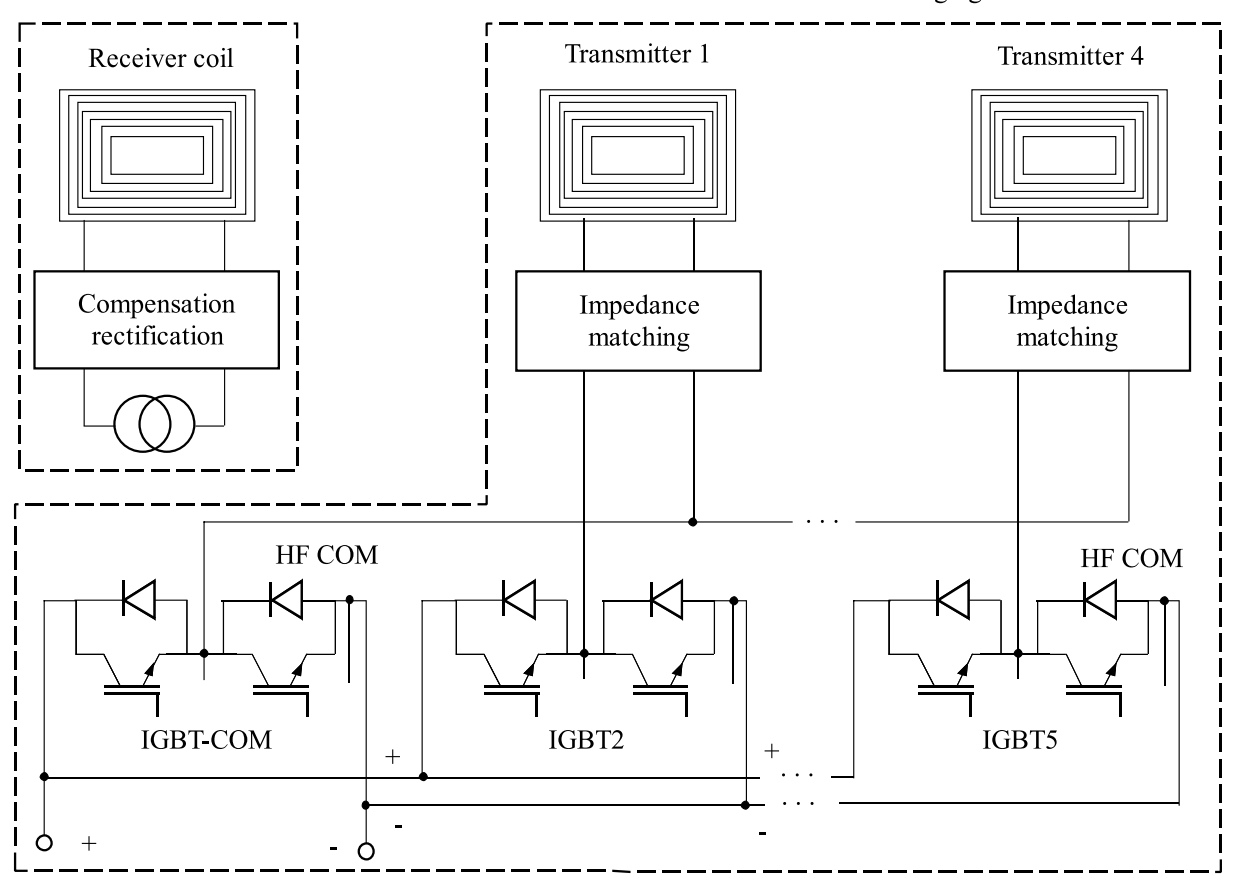

Fig. 3. IPT power converter topology

is $45 \mathrm{~kW}$ with maximum vertical distance of $90 \mathrm{~mm}$ and full horizontal alignment. In practice such levels of transferred power makes this prototype forefront of the competition along with many companies producing systems for contactless charging of EVs. From Fig. 5 can be seen the strong dependence of the overall system efficiency on the horizontal misalignment.

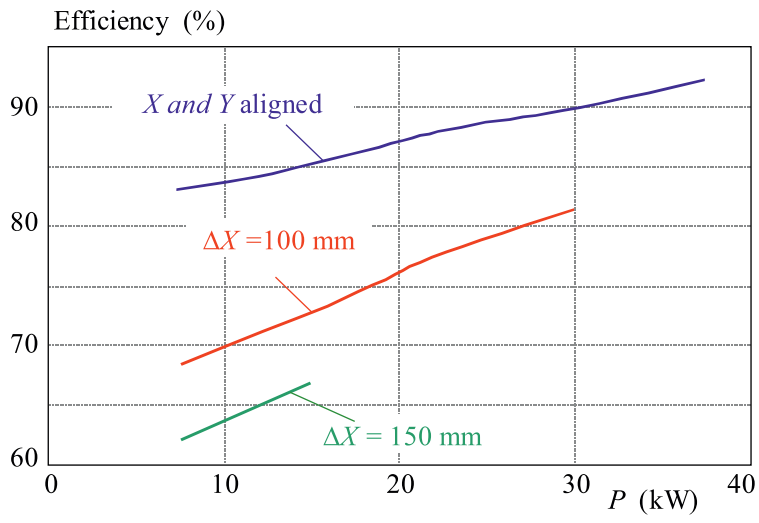

Fig. 4. IPT system efficiency

There are two main reasons: distortion of the magnetic field between primary and secondary coils, causing bad magnetic coupling and increasing the magnetizing current - respectively copper losses. The efficiency value is better when the transferred power is near to its nominal value. Reason for that are relatively linear change of power losses, major part from which are copper and ferrite losses in the windings. At nominal power commu- tation of the IGBTs is near to zero cross point (ZCS) and transistor power losses are smaller [6-8].

Key feature of the developed from the research team in Technical University of Gabrovo, Bulgaria system is its ability to transfer energy while running ("on route" charging). The main parameters in sensorless "current mode" algorithm for switching between coils can be described with the following parameters

$$
L_{o f f}=L_{c o i l}-E P T+D_{c o i l}
$$

where: $L_{\text {off }}$ - is the length of the path between coils along which the system does not transfer energy, $L_{\text {coil }}-$ is the length of the coil, $D_{\text {coil }}$ - is the distance between end point of a coil and the starting point of the next coil, $E P T$ - is important, in practice it determines the pathlength of the most efficient energy acquisition during the charging process and can be used as a point for transition between the coils, [9].

Transferred energy is proportional to the vehicle speed and the energy acquisition over the so called EPT area and can be estimated as

$$
E_{o n}=\frac{t_{o n}}{E P T} \int_{E P T} P(x) \mathrm{d} x,
$$

where $P(x)$ - is the power transferred at a given position (depending on the instantaneous magnetic coupling due to the motion), and $t_{o n}$ - is the time needed to travel the EPT- distance. Following example can be given, take: $L_{o n}=E P T=160 \mathrm{~mm}, D_{\text {coil }}=200 \mathrm{~mm}$ and, $L_{\text {coil }}=800 \mathrm{~mm}$, then ${ }_{\text {Loff }}=840 \mathrm{~mm}$. Here the optimization of the transmitting coils dimensions and the distance between them is essential. 


\section{CONCLUSION}

This article demonstrates the progress in scientific research and development of the converter for contactless charge, providing quick charge of the electric vehicle batteries in both modes - during movement on the road and statically. The results achieved in the particular scientific development placed her among the first places in the area. One of the achieved main goals is the mock-up of charging station showing the real energy transfer of power $30 \mathrm{~kW}$ at $70 \mathrm{~mm}$ air gap, Fig. 5 .

The achieved results are encouraging and one of future directions to develop a production model of the charging station for the static and on-route charging of electric vehicles operating in real urban environments [9], which is in line with the objectives of the project FastInCharge under the FP7 program.

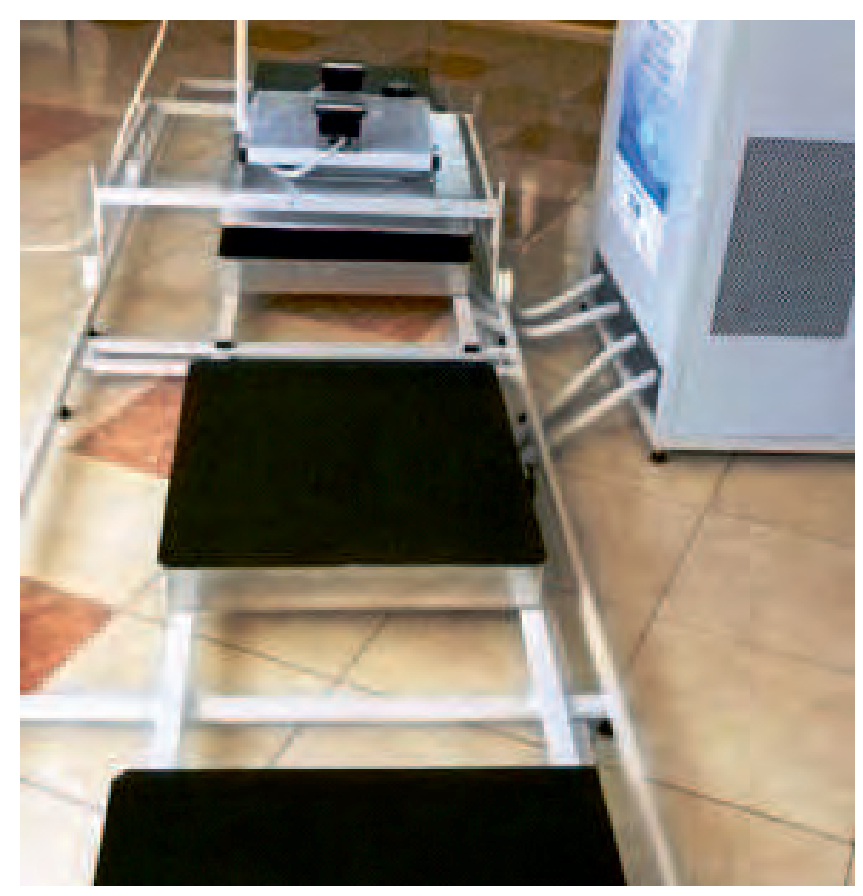

Fig. 5. Demonstration of the complete IPT system for static and on-route charging of EVs Converter 4 in 1, Transmitting coils (4 pcs), Receiver coil with rectifier and halogen indication, $30 \mathrm{~kW} \mathrm{~mm}$.

\section{REFERENCES}

[1] MADZHAROV, N. D.-TONCHEV, A. T. : Contactless Charging System For Electric Vehicles, TU of Gabrovo, International Scientific Conference PCIM'12, Nurnberg, Germany, 2012.
[2] KRAEV, G.-HINOV, N.-ARNAUDOV, D.-RANGUELOV, N.-GRADINAROV, N.: Multiphase DC-DC Converter with Improved Characteristics for Charging Supercapacitors and Capacitors with Large Capacitance, Annual Journal of Electronics, V6,B1,TU of Sofia, Faculty of EET, ISSN 1314-0078 (2012), $128-131$.

[3] McLYMAN, W. T.: Transformer and Inductor Design Handbook,Kg Magnetics Inc. Idillwild, California,USA.

[4] Patent WO 2006/048441, Sealing Device For Producing Sealed Packages of a Pourable Food Product, Valentin Nemkov (Fluxtrol, USA), Nikolay Madzharov (TU, BG).

[5] Throngnumchai, K.-KAI, T.-MINAGAWA, Y.: A Study on Reciever Circuit Topology of a Cordless Battery Charger for Electric Vehicles, Nissan Research Center, Nissan Motor Company.

[6] MAdzharov, N. D.-TONCHEV, A. T. : Matching the RF Transformer to Contactless Charging Converter for electric Vehicles TU Gabrovo, PCIM 2013 Nurnberg, Germany.

[7] KRAEV, G.-HINOV, N.-OKOLIYSKI, L. : Analysis and Design of Serial ZVS Resonant Inverter, Annual Journal of Electronics,V5,B1,TU Sofia, Faculty of Electronic Engineering and Technologies, (2011), 169-172.

[8] BANKOV, N.-VUCHEV, AL.-TERZIYSKI, G. : Operating modes of a series-parallel resonant DC/DC converter, Annual Journal of Electronics, Sofia 3 No. 2 (2009,), 129-132.

[9] Innovative fast inductive chargingsolution for electric vehicle Smart infrastructures and innovative services for electric vehicles in the urban grid and road environment, part of 7th Framework Program of EU, www.fastincharge.eu.

Received 20 September 2013

Nikolay Madzharov received the MSc, PhD and Assoc Prof degrees in power electronics in 1987, 2002 and 2004 respectively. He is the Associate Professor at the Faculty of Electrical Engineering and Electronics, Technical University in Gabrovo, Bulgaria. His research interests include development of transistor transducer devices with improved matching capabilities and their applications in various advanced technological processes with induction heat - sealing of packaging for the food industry, soldering heaters, diamond tools and other specific details of the high melting metals (platinum) and alloy cutters techniques, new technologies for parts recycling and electrical vehicles.

Anton Tonchev received the BTech and MTech degree in Electronics in 2006 and 2010 respectively from Technical University of Gabrovo, Bulgaria. He has been involved in various research activities in the area of Power Electronics Induction Heating Power Supply Systems, SMPS and Ultrasonic Power Converters. He is PhD student in Technical University of Gabrovo, Bulgaria from 2011. 